\title{
TEORIA CRÍTICA E DIDÁTICA: UM DESAFIO PARA A EDUCAÇÃO CONTEMPORÂNEA ${ }^{1}$
}

\author{
Carolina Maranhão ${ }^{2}$ \\ Flávia Carolini Pereira dos Santos ${ }^{3}$ \\ Pedro Nunes Gouveia ${ }^{4}$
}

http://dx.doi.org/10.1590/1413-2311.186.65575

\section{RESUMO}

Este artigo se propõe a tecer reflexões sobre a semiformação, estado em que se encontra o ensino superior, apresentando a didática crítica de Gruschka (2014) como alternativa crítica, capaz de recuperar o potencial de esclarecimento da educação. Para tal, pautou-se a discussão através dos estudos críticos de Adorno (1996) em seu ensaio conhecido como a Teoria da Semicultura (1959). A massificação cultural invadiu o sistema educacional cuja formação técnica e racional se multiplicou e resultou na banalização de práticas que revelam a degradação de espaços - como a sala de aula - que originariamente deveriam permitir a capacidade da autorreflexão, em locais de doutrinação instrumental de artifícios que postulam os alunos às exigências do mercado e aos imperativos de uma sociedade totalmente imersa no consumismo. Criou-se uma formação na qual todos os interesses se aliaram ao capital - a ideia de que o sujeito quanto mais ajustado ao seu estilo de vida à lógica do capital, mais produtivo se tornava. Restou para a educação contemporânea o desafio de permanecer na reflexão crítica quando seu ambiente já está tomado pelo semiformação.

Palavras-Chave: Semiformação. Teoria Crítica. Didática. Educação.

\footnotetext{
${ }^{1}$ Recebido em 11/07/2016, aprovado em 02/01/2018.

${ }^{2}$ Universidade Federal de Ouro Preto (Brasil) - carola.maranhao@gmail.com

${ }^{3}$ Universidade Federal de Ouro Preto (Brasil) - laviapereirasantos2011@hotmail.com

${ }^{4}$ Universidade Federal de Ouro Preto (Brasil) - nunesgou@hotmail.com.br
} 


\title{
CRITICAL THEORY AND TEACHING: A CHALLENGE FOR CONTEMPORARY EDUCATION
}

\begin{abstract}
This article proposes to reflect on the semi-formation, state of higher education, presenting the critical didactics of Gruschka (2014) as a critical alternative, capable of recovering the potential of education clarification. For this, the discussion was guided by the critical studies of Adorno (1996) in his essay known as The Theory of Semiculture (1959). Cultural massification has invaded the educational system, whose technical and rational formation has multiplied and resulted in the trivialization of practices that reveal the degradation of spaces such as the classroom - that originally should allow the capacity of self-reflection, in places of instrumental indoctrination of artifacts that postulate students to the demands of the market and the imperatives of a society totally immersed in consumerism. A formation was created in which all interests were allied with capital - the idea that the subject, more adjusted to his way of life, to the logic of capital, became more productive. The challenge of remaining in critical reflection has remained for contemporary education when its environment is already taken by semi-formation.
\end{abstract}

Keywords: Semi-formation. Critical Theory. Teaching. Education.

\section{TEORÍA CRÍTICA Y DOCENCIA: UN DESAFÍO PARA LA EDUCACIÓN CONTEMPORÁNEA}

\section{RESUMEN}

Este artículo se propone a tejer reflexiones sobre la semi-formación, estado en que se encuentra la enseñanza superior, presentando la didáctica crítica de Gruschka (2014) como alternativa crítica capaz de recuperar el potencial de esclarecimiento de la educación. Para ello, se basó la discusión a través de los estudios críticos de Adorno (1996) en su ensayo conocido como la Teoría de la Semicultura (1959). La masificación cultural invadió el sistema educativo cuya formación técnica y racional se multiplicó y resultó en la banalización de prácticas que revelan la degradación de espacios - como el aula - que originariamente deberían permitir la capacidad de autorreflexión, en lugares de adoctrinamiento instrumental 
de artificios que postulan a los alumnos las exigencias del mercado y los imperativos de una sociedad totalmente inmersa en el consumismo. Se creó una formación en la que todos los intereses se aliaron al capital - la idea de que el sujeto como más ajustado a su estilo de vida a la lógica del capital, más productivo se convertía. Resta para la educación contemporánea el desafío de permanecer en la reflexión crítica cuando su ambiente ya está tomado por la semiformación.

Palabras-clave: Semi-formación. Teoría Crítica. Enseñanza. Educación.

\section{INTRODUÇÃO}

A mercadorização da sociedade através das práticas pedagógicas culturalmente industrializadas é um tema polêmico e contundente que provoca pesquisadores, filósofos e sociólogos há anos. O objetivo deste estudo é propor reflexões sobre a semiformação, estado em que se encontra o ensino superior, apresentando a didática crítica de Gruschka (2014) como alternativa crítica capaz de recuperar o potencial de esclarecimento da educação. É preciso se questionar: o que está havendo nas salas de aula? Que tipo de consciência discente está sendo formada nos ambientes de ensino?

A busca pelas respostas dessas indagações se dará através dos estudos críticos de Adorno (1996), bem como pelas proposições mais recentes de Gruschka (2014) ao investigar a sala de aula e como uma nova pedagogia assinalaria a tão desejada transformação do ambiente de ensino e aprendizagem, configurando-se como alternativa através da recuperação da prática formativa. Acosta, Tóbon e Loya (2015) afirmam que existe uma correlação entre prática socioformativa e o desempenho dos discentes. Portanto, essa prática formativa influencia a forma como os alunos aprendem e compreendem a realidade.

A reflexão crítica da semiformação proposta por Adorno (1996) volta-se para o estudo da criação pela sociedade contemporânea - como define Pucci (2009) - de uma verdadeira massificação e tecnologização da educação, fruto da tentativa política de tornar o ensino acessível a todos por meio da padronização da aprendizagem. Consequentemente, a pedagogia semiformativa presente no atual sistema educacional limita-se a uma contemplação passiva marcada pela falta de elementos que garantiriam um aprendizado autônomo e consciente. 
A perversa lógica da semiformação se baseia no uso de artifícios, principalmente nas últimas décadas com a evolução dos aparatos tecnológicos, que facilitam ainda mais a instrução. A tecnologia que veio com a ideia de facilitar a vida do ser humano ultrapassa seus limites no ambiente escolar através de vídeos, livros didáticos e softwares educativos, ocupando o lugar e autoridade do professor na sala de aula, assumindo a centralidade da bagagem formativa dos discentes. Além disso, a inserção desenfreada da cultura digital no espaço escolar, cuja marcante característica, definida por Lastória et al. (2013), é o bombardeamento de informações, capaz de transformá-la em um notável canal transmissor de formação de opinião para a maioria dos alunos. Entretanto, não se trata da construção de uma formação destinada à emancipação dos sujeitos, mas de uma irreflexão enviesada pelos interesses do sistema capitalista, que aliena os princípios de liberdade e consciência inerentes à Eeucação.

Segundo Pucci (2009), o aluno submete-se às exigências de uma formação funcionalista que o classifica como produtivo, adaptando-o ao sistema que subtrai suas forças e diminui sua autonomia crítica e livre de sujeito. Perde-se, portanto, todo resquício de relação socrática entre o aluno e professor - a maiêutica, a arte de trazer à luz - quando a transmissão do conhecimento ajuda o aluno na reflexão e descoberta de si mesmo através da concepção de suas próprias ideias e não apenas da tradução de fatores pré-estabelecidos pela lógica do capital, que coíbem bruscamente seu pensamento emancipatório.

Frente ao cenário apresentado, propõe-se a discussão sobre o caminho enviesado que a educação contemporânea está passando ao se afastar da reflexão crítica e se aproximar cada vez mais da sua própria banalização ao usar artifícios advindos do capitalismo e transfigurar suas práticas pedagógicas em semiformação. Compreende-se que há um ciclo se repetindo, a escola está se tornando uma grande indústria no sentido de fábrica de produção em massa, os discentes entram leigos e saem leigos. A diferença é que na instituição de ensino eles são moldados, fabricados e timbrados para atender como mão de obra e atingir objetivos econômicos que nada se relacionam com a sua formação crítica. Ordorika e Lloyd (2014) afirmam que as universidades passam por tensões estruturais. Nessa ideia, não há indivíduo, não há subjetividade, há uma grande massa vazia que produz matéria prima discente e docente que retornam para a produção nos ambientes de ensino.

Esse artigo tem seus olhos voltados para o ensino em Administração. Mas por que essa escolha? A resposta dessa pergunta pode-se encontrar também nos estudos de Saraiva (2011, p. 42). Além de ser um dos cursos com mais alunos matriculados no Brasil, existe uma fetichização dessa profissão, já que "no mundo dos negócios, o crescimento exponencial de 
cursos de Administração transformou esta área na locomotiva da educação superior brasileira, (...), também pelas prováveis altas taxas de retorno associadas aos seus baixos custos operacionais".

A forma pedagógica dos cursos de Administração apresenta características de um processo produtivo no qual se dividem dois insumos: os alunos que sonham em ter uma formação superior e os professores aptos que já possuem tal formação. Os produtos são estudantes já 'prontos', que passaram por todo o processo de fabricação de mão-de-obra para o mercado. Quanto mais discentes fabricados maior é o sucesso dessas instituições ou ‘fábricas'. Esse ciclo se repete continuamente. Destarte, o "ensino de administração mais treina do que educa, e, com isso, deixa implícita a predominância da ética do mercado em detrimento da humana, base para a emancipação do homem" (SARAIVA, 2011, p. 52).

Paula e Rodrigues (2006, p. 11), ao analisarem os estudos de Alcadipani e Bresler (2000) corroboram que o ensino em Administração brasileiro está influenciado pelo processo de “macdonaldização". Eles ainda afirmam que "muitas instituições não se importam mais com a qualidade da produção ou da formação, mas com os números de cursos, de matrículas e de aprovações. Nesse processo, a tecnologia de fastfood é utilizada para padronizar informações e maximizar a quantidade de alunos. Nas 'universidades-lanchonete', professores 'adestrados' apresentam 'receitas de bolo' e 'doutrinas sagradas'dos manuais de gestão".

Gruschka (2014) aponta uma possível recuperação crítica dos sujeitos ao propor a concepção de uma nova didática, baseada nos limiares críticos adornianos. Essa pedagogia assinalaria a tão desejada transformação do ambiente da sala de aula, configurando-se como a melhor alternativa para desvincular interesses econômicos da educação, através da recuperação da prática formativa. Se todos soubessem como é importante quando um professor traz para sua aula questionamentos críticos capazes de incomodar seus alunos e provocar a procura de respostas, capazes de ensinar a questionar o mundo externo à sua vida acadêmica, a educação deixaria de ser mero instrumento para se tornar uma alavanca para a liberdade, autenticidade e aporte de uma consciência crítica.

Sendo assim, a pedagogia crítica seria uma alternativa de renovação para o ensino em Administração. Esse outro tipo de abordagem proporcionaria a revisão de vários elementos que já se encontram defasados, pouco explorados ou inexistentes, tais como "os conteúdos, os métodos pedagógicos, a ligação entre teoria e prática, e principalmente o desenvolvimento da visão crítica e do raciocínio analítico entre os estudantes de Administração" (PAULA e RODRIGUES, 2006, p.14). 


\section{REFERENCIAL TEÓRICO}

\subsection{TEORIA CRÍTICA E ADORNO: REFLEXÕES À LUZ DA TEORIA DA SEMICULTURA (1996)}

De acordo com Vilela (2006, p. 12), a relação de elementos que formam o termo Teoria Crítica "refere-se ao conjunto sistemático de posições teórico-científicas, produzidas pelo grupo originário do ISF e, mais notavelmente, por Adorno e Horkheimer: a fundamentação dialética da problemática teoria e prática para investigar e analisar as relações sociais". A Teoria Crítica é uma identidade epistemológica que se contrapõe a Teoria Tradicional. Tal teoria atuava como dominante na forma de se pensar como se configurava a relação da sociedade.

Pucci (2001, p. 3) expõe que "o termo "teoria crítica" se consagrou a partir do artigo de Max Horkheimer, em 1937 - Teoria tradicional e teoria crítica, em que o autor prefere utilizar essa expressão para fugir da terminologia "materialismo histórico". Vilela (2006, p. 13), ao apresentar os estudos de Adorno Horkheimer, aponta que a Teoria Tradicional fundamentada no Positivismo:

[...] fornecia uma análise descontextualizada e com pretensão de universalidade, reproduzindo uma imagem fetichista do mundo, tal como ele era numa categoria de aparentemente dado (das ist), assim o justificava e o reproduzia. Como contraponto, uma Teoria Crítica, tal como era formulada no ISF de Frankfurt, fundava uma ciência contextualizada, não neutra, engajada na transformação do mundo. A Teoria Crítica visava apreender a sociedade e suas instituições na totalidade da vida social concreta, buscando desvendar as relações dos acontecimentos sociais na dialética das relações sociais historicamente determinadas.

Fabiano e Silva (2012, p. 1072) enfatizam que a "Teoria Crítica propõe uma análise da racionalidade técnica dominante no contexto da sociedade industrial e as implicações ideológicas da produção cultural na formação da consciência social”, ou seja, essa corrente de pensamento contribui com essa pesquisa ao analisar como o capitalismo 
impactou a sociedade ao facilitar a adulteração da formação cultural do sujeito, a ponto de transformá-la não em uma falsa formação, mas numa semiformação determinada e entendida como certa, o que torna esse processo pior do que se não houvesse formação cultural. É justamente neste ponto que se busca entender o porquê da banalização da educação, o caminho perdido que a transformou em objeto e sua relação com os estudos críticos adornianos. Destarte,

[...] esse pressuposto teórico torna-se fundamental para uma reflexão crítica sobre a educação, entendida como instrumento de disseminação e legitimação da produção cultural. As questões ideológicas no plano da cultura constituem para o pensamento frankfurtiano um elemento fundamental da crítica à racionalidade técnica, pois está na ideologia mercantil a raiz da irracionalidade que alimenta a barbárie social (FABIANO; SILVA, 2012, p. 1072).

Um dos estudos de maior relevância para esta pesquisa e para a Teoria Crítica em educação é o escrito por Adorno (1996), cunhado como a Teoria da Semicultura, no qual o frankfurtiano revela a decadência da cultura e da educação numa sociedade administrada e industrializada. Correia (2016, p.112) explica que no estudo adorniano, o filósofo alemão concluiu que "o esclarecimento - enquanto proposta - desembocou, assim, num processo de semiformação (Halbbildung) que provocou a perda da identidade e a reificação do indivíduo". Portanto, a semiformação é o resultado do esvaziamento da formação. E reforça que este esgotamento da formação está relacionado aos "controles sociais provocados pela racionalidade ocidental, pela utópica promessa do sapere aude, que ao invés de conduzir o sujeito à autonomia, realizou o inverso: o controle e a dominação. Para ele, a Indústria Cultural (Kulturindustrie) é a principal promotora desta dominação, ou seja, desta sujeição do ‘sujeito' à sociedade administrada”.

Pucci $(2001$, p. 7) afirma que o processo da semicultura é muito mais extenso do que se imagina. Segundo o autor, "não são fenômenos apenas educacionais, ideológicos, espirituais; atingem as relações sociais em todas as suas dimensões”. A crise instaurada não pertence a um mundo particular, a crise da educação está na sociedade que se transformou em semiformada e teve seu espírito alienado. Vilela (2006, p. 45) corrobora com essa afirmativa ao frisar: 
[...] a crise da educação é a crise da formação cultural da sociedade capitalista, uma formação na qual o homem é alienado, mesmo que tenha sido educado (escolarizado/instruído). A educação vigente é uma semiformação, na medida em que, na sociedade industrial capitalista, o indivíduo foi destruído e só prevalece à massa, o coletivo, o tudo igual. O indivíduo de Adorno, sob o império da Indústria Cultural, perdeu o que há de essencial no humano: a capacidade de subjetivação e, por isso, perdeu também a capacidade de solidariedade, de respeito, perdeu a dignidade. Foi essa alienação que tornou possível o nazismo, o holocausto e os campos de concentração, porque ela fabrica sujeitos alienados, incapazes de uma relação subjetiva e crítica com sua realidade, ela aumenta o potencial de adesão sem consciência.

Adorno (1996, s.p.) reforça que "a ideia de cultura não pode ser sagrada — o que a reforçaria como semiformação - , pois a formação nada mais é que a cultura tomada pelo lado de sua apropriação subjetiva”. A cultura assume duplo caráter, segundo Bandeira e Oliveira (2012, p. 228) "ela é, ao mesmo tempo, adaptação, conformação à vida real e autonomia, liberdade do sujeito". Pucci (2001, p. 6) explica que, na visão adorniana, a "cultura, ao mesmo tempo que se impregna do húmus e do fluir descompassado de seu momento (integração), dele procura se afastar para respirar e desvendar sua insensatez (autonomia)". Quando um desses momentos se sobrepõe ao outro, abre-se a possibilidade da instauração da semiformação.

Se, por um lado, a Bilduing teria a missão de promover a emancipação proposta por um ideal de uma sociedade igualitária e justa; por outro, ao notar o fracasso dos ideais iluministas propostos pela burguesia e com a evolução do capitalismo, trouxe uma nova cultura que transformou os produtos culturais em valores de troca, "na linguagem da filosofia pura, a cultura se converteu, satisfeita de si mesma, em um valor” (ADORNO, 1996, s.p.).

É importante salientar que, se a cultura se transformou em algo adaptável, é porque o produto cultural perdeu seu brilho, deixou de ser único e foi dissolvido até se tornar algo que não é; perdeu seu valor de uso para ser resumido em um valor de troca, uma mercadoria que não se expressa somente em si, mas em todas as relações sociais. Essa manobra aconteceu para preencher o espaço vazio da vida do trabalhador nos seus momentos de lazer. Assim, ele não poderia pensar nas injustiças do sistema, se tornando alienado e 
acrítico. Portanto, em uma sociedade em que se consome tudo o que é materializado, na verdade não se consome nada que poderia ser útil para a sua formação com sujeito esclarecido. Isso só aumenta o vazio e a sensação de querer mais, pois acredita-se que em algum momento se encontrará a felicidade plena. Segundo Guimarães, Santana e Motta (2012, p. 36) "o homem acredita dominar a natureza externa, mas não consegue dominar sua natureza interna, que fica subjugada à lógica do capitalismo, pois diante da instrumentalização da razão e coisificação do sujeito, o máximo que se consegue com o suposto esclarecimento é a semiformação humana".

Adorno (1996) levanta uma questão importante: não se pode deixar que a vontade de mudar a atualidade 'atolada' nos problemas da sociedade se torne somente um sonho, um mito, algo que nunca poderá se realizar. Porém, conforme Bandeira e Oliveira (2012, p. 229), não é isso que ocorre, "o ideal da formação esconde o que na prática não se realiza". A Semicultura teve início nesse momento em que a burguesia entregou um fetiche, algo que não se realizaria e novamente perdeu-se um momento histórico que poderia ser realizado.

Vilela (2006, p. 54) afirma que "na sociedade industrial capitalista, o indivíduo foi destruído e só prevalece a massa, o coletivo, o tudo igual". Vários instrumentos são usados pela Indústria Cultural para distorcer a formação dos indivíduos: os meios de comunicação como rádio e a televisão, revista, jornais, livros e etc. Newman (2015) afirma que o sentido conotativo das imagens da mídia tem um significado mais profundo e os indivíduos semiformados não alcançam o seu entendimento. Os bens culturais foram transfigurados e padronizados em mercadorias para atender o consumo em massa.

Os meios de comunicação se especializaram em expor temas educacionais de forma vazia, o que só aumentou sua banalização. "O resultado desse processo é o desaparecimento do potencial crítico, esclarecedor e criativo da educação produzindo, de fato, uma 'semicultura', e seu resultado é a 'semiformação' (VILELA, 2006, p. 55).

Pode-se concluir que, ao tratar a educação como práxis dos indivíduos, as definições de formação cultural e educação tornam-se inseparáveis para auxiliar na construção do sujeito. Segundo Bandeira e Oliveira (2012, p. 233) "a educação, como processo de formação, possibilita ao homem inserir-se no fluxo histórico-cultural como sujeito, servindo-se do próprio entendimento, sem a tutela de outrem”. O que os autores afirmam é que a educação pode recuperar o seu momento histórico de 'salvar' o homem das amarras opressoras do capitalismo ele se reconhecer como sujeito questionador das injustiças sociais. Adorno (1996) propõe, no fim do seu estudo, uma alternativa para o resgate da 
formação cultural: "a única possibilidade de sobrevivência que resta à cultura é a autorreflexão crítica sobre a semiformação, em que necessariamente se converteu”.

\subsection{DIDÁTICA CRÍTICA: UM ESTUDO ATRAVÉS DE GRUSCHKA}

É nítida a percepção de que o sistema educacional contemporâneo é regido pelos imperativos de ordem econômica que, marcada por seu pragmatismo característico, não permite a subjetividade na formação de pensamentos críticos e autossuficientes. Por meio dessa premissa, o professor da Universidade de Frankfurt e especialista em Teoria Crítica Andreas Gruschka (2014) propõe uma didática baseada nos limiares críticos propostos por Adorno (1996). Essa pedagogia assinalaria a tão desejada transformação do ambiente da sala de aula, configurando-se como alternativa para desvincular interesses monetários da formação, através da recuperação da genuína prática formativa.

Vilela (2009, p. 56) reúne em seu Relatório de Pesquisa uma investigação dos estudos de Gruschka (2014) na crítica à pedagogia crítica. A autora corrobora com este artigo ao "conhecer a produção de Gruschka como intérprete da relação Teoria Crítica e Educação; verificar sua produção de pesquisa empírica sobre a realidade educacional na Alemanha, na atualidade para compreender como está subsidiada em Adorno".

De acordo com Vilela (2009), os artigos de Gruschka (2009) publicados na revista Pädagogische Korrespondenz de 1987 a 2000 mostram a filiação do pesquisador à Teoria Crítica de Adorno e também a relevância que dava a Heydorn, pedagogo crítico, e a Blankertz, teórico crítico. Na quarta edição da revista em 1988/89, Gruschka (2014) retoma em seus estudos os ideais da criação da sua revista e constrói um artigo que pretende:

[...] constrastar a pretensão de abertura e de liberdade para as escolas

e sua subordinação a currículos estandardizados, o que seria o contrassenso para a pretensa liberdade da escola e de sua condição de formar pessoas para a vida democrática, o que era bandeira dos educadores críticos. Discute a tendência vigente para normatizar a escola e o currículo e aponta questões em alguns modelos de escolas implantadas em diferentes lugares na Alemanha, que se apresentavam como sendo diferentes do padrão, em relação ao currículo e à qualidade da prática pedagógica. (...). Segundo o autor, desde que as esperanças depositadas nas reformas não foram confirmadas, a 
tendência era tentar arrumar questões menores dentro das escolas, depositando o fracasso na ação pedagógica incorreta. Mas, segundo ele, não se tratava de melhorar a escola para que os alunos pudessem fazer novas e diversificadas experiências. $O$ que os modelos de escolas reformadas editavam como programas inovadores não passavam de pequenos passos incapazes de superar a falha da experiência formativa (segundo a Bildung) dentro delas (VILELA, 2009, p. 64).

Segundo Carvalho (2013, p. 50), ao referir-se aos estudos da teoria de Gruschka (2014), “[...] a dialética entre escola e sociedade caracteriza-se, na sociedade contemporânea, por um processo de subsunção da Educação à Economia, no qual a escola incorpora ideias e procedimentos tipicamente industriais". Tal processo provoca alterações na forma que os educadores interagem com o conhecimento. Assim, a didática se sobrepõe em relação aos conteúdos e muda a direção da formação.

Vilela (2009) informa que Gruschka (2014) escreveu três livros com contribuições dos estudos de Adorno para a educação. São eles: "Pedagogia Dialética Introdução à Pedagogia com a Teoria Crítica" escrito em 1988; "Frieza burguesa e Pedagogia: moral na sociedade e na educação" escrito em 1994; e "Didática, a cruz do processo de ensinar - onze reivindicações contra o fazer didático" publicado em 2002. Segundo a autora,

Para os familiarizados com a obra de Theodor Adorno, os títulos já confessam a vinculação da produção de Gruschka à Teoria Crítica. Mas a análise desses livros permite compreender porque o sociólogo educacional Andreas Gruschka é identificado como um nome que teria dado novo impulso para a uma Ciência da Educação crítica, sustentada pela teoria social dos frankfurtianos, motivando uma vasta produção de pesquisas empíricas da realidade educacional no país (VILELA, 2009, p. 68).

As pesquisas empíricas de Gruschka (2014) utilizam uma das abordagens mais conhecidas em pesquisa qualitativa: a Hermenêutica Objetiva (GOMES, 2015). Trata-se de "uma variante de pesquisa sociológica qualitativa que foi desenvolvida pelo Prof. Ulrich 
Oevermann, da Universidade de Frankfurt, e adaptada à situação empírica da sala de aula pelo Prof. Andreas Gruschka" (GOMES, 2015, p. 151).

Gomes (2015, p. 151) explica que "a Hermenêutica Objetiva orienta-se pelas premissas fundamentais da 'Dialética Negativa', de Theodor Adorno (2009)". Uma delas corresponde afirma que

[...] a crítica da sociedade é crítica do conhecimento sobre a sociedade e a crítica ao conhecimento sobre a sociedade, é também crítica da sociedade. Portanto, fazer pesquisa social é um empreendimento que visa compreender como estão associadas a reflexão teórica fornecida pela Teoria Crítica e os dados empíricos que a viabilizaram, como teoria e como projeto de pesquisa social (GOMES, 2015, p. 2).

Portanto, o propósito da Hermenêutica Objetiva é revelar o sentido daquilo que está evidente, exercitar a dialética negativa e assim levar ao esclarecimento da realidade (VILELA, 2012).

Gruschka (2014, p. 5) procurou estabelecer no sistema educacional alemão um oásis da prática formativa separada da didática por meio de projetos que estabelecessem o "[...] renascimento da Teoria Crítica aplicada à educação", como a Pädagogische Rekonstruktiondes Unterrichtens (Reconstrução Empírica da Aula) - PÄERDU. Seu objetivo principal é a "[...] reconstituição empírica da situação pedagógico da aula, com o propósito de revelar o sentido do processo formativo na escola de hoje" (GOMES, 2015, p. 152).

Tranier (2013), ao relembrar o tratamento dado à educação durante a crise vivida por seu país, a Argentina, em 2001, destaca o fato das políticas educacionais que primam essencialmente pelo viés financeiro se transformarem nas principais responsáveis pela alienação e mortificação do trabalho de educar. Como afirma Gruschka (2009), na contemporaneidade, a relação entre escola e sociedade é caracterizada por um processo de submissão da educação à economia. Ou seja, compõe-se um cenário no qual a didática se sobrepõe à forma dos alunos absorverem o aprendizado conduzido por um imperativo em que a mediação entre o sujeito e o objeto a ser conhecido é dirigido pedagogicamente de acordo com objetivos pré-determinados. Nessa lógica, em que prevalece a razão instrumental, a heteronomia e a semiformação; o conteúdo do ensino e da formação são impostos pelo mercado, que define as competências que devem ser apreendidas” (GOMES, 2015, p. 152). 
A mediação originária, não dirigida pedagogicamente, entre objeto e sujeito - que para Humboldt deveria ser a mais livre e distinta ação recíproca, para que algo como a educação de um sujeito se tornasse possível e não apenas acomodação a um saber, uma prática, a aceitação de um significado - é então racionalizada por meio da inserção de um magistral terceiro termo: a didática (GRUSCHKA, 2009, p. 151).

Através de uma minuciosa análise dos métodos que embasam o processo pedagógico nas salas de aula do ensino secundário germânico e a constatação da subserviência da educação ao mercado, o projeto lança bases para uma metodologia que prime pela “Erziehung-Didatik-Bildung” (Educação-Ensino-Formação).

Gruschka (2014) aponta como uma possível saída a essa invasão instrumental nas salas de aula um contraprojeto cuja exigência prática é "Ensinar a compreender". Para que isso se realize, o autor apresenta uma tarefa dupla:

De um lado, trata-se de reconstruir empiricamente como se apresenta "a compreensão" na sala de aula, e de outro lado, estou fazendo isso pelo fato de que "compreender" até hoje representa o Telos central da educação escolar. "A compreensão" não será imposta como uma norma idealista às aulas, mas representa seu motivo de ser (raison d'être), que talvez seja o elemento que mais tenha sentido. Quem quiser avaliar o significado do ensino, precisa extrair cientificamente as condições da possibilidade do aprendizado em sala de aula (GRUSCHKA, 2014, p 7).

Na sessão a seguir, apresenta-se como Gruschka (2014) oferece mais um aporte na luta contra semiformação no ambiente escolar.

\subsection{A DIDÁTICA CRÍTICA COMO UMA SAÍDA À SEMIFORMAÇÃO}

A manifestação de grandes crises no conhecimento cultural dos indivíduos, definida por Adorno (1996) como um processo de semiformação socializada, não se estabelece apenas como um entrave na educação. Como foi evidenciado nos tópicos 
anteriores, tolhe o desejo de liberdade e emancipação característicos de uma sociedade autônoma. Portanto, a pedagogia alinhada à Teoria Crítica pode ser uma possibilidade de “[...] uma reforma democrática da educação, à desconstrução do sistema existente de privilégios, à modernização do currículo, à liberalização do relacionamento entre as gerações" (GRUSCHKA, 2014, p. 4).

Gruschka (2014) retoma o valor da crítica à semiformação no ambiente acadêmico sob a perspectiva das desmedidas intervenções dos interesses de capital privado sobre o processo de inoculação do saber apresentadas nos reiterados financiamentos das atividades e produção científicas oriundas dos estabelecimentos públicos de ensino. O mesmo autor alvitra uma reformulação do ambiente estrutural da sala de aula, salientando o desejo de educar em detrimento dos retornos dos investimentos financeiros. Destarte, na crítica atual, "[...] não é o objetivo da emancipação, mas o economicismo que questiona as relações de ensino sob o critério da sua funcionalidade para o sucesso econômico" (GRUSCHKA, 2014, p. 4).

De acordo com Gruschka (2014), houve um movimento que mostrou as instituições e à sociedade a invasão negativa dos interesses econômicos para a educação. $\mathrm{O}$ autor esclarece que esse movimento levou à retomada da Teoria Crítica e a um questionamento do objetivo da pedagogia. Gruschka (2014, p. 5), então, esclarece que “[...] surge um contra movimento que se desenvolve na consciência da perda e da necessidade absoluta do projeto da emancipação cívico através da educação e da formação".

Gruschka (2014) estuda empiricamente este tema há pelo menos 30 anos. Começou a pela construção de um manifesto intitulado "Pedagogia Negativa", que discutia quais os novos direcionamentos da pedagogia alinhados ao pensamento dos estudiosos críticos. Essa primeira pesquisa orientou os outros trabalhos do autor, ao destacar a educação difundida no ambiente escolar "[...] no sentido de analisar aquela produção de frieza, à qual, segundo Adorno/Horkheimer, a formação da subjetividade burguesa em nossa época é submetida" (GRUSCHKA, 2014, p. 6). Após algumas pesquisas empíricas sobre a produção da frieza, o autor chega à obra "Crítica da Didática" e, logo em seguida, a um estudo que mostrou a realidade das escolas alemães. Ao realizar esta pesquisa, constatou que a escola era mantida como “[...] possível espaço de esclarecimento transformada em um centro de reprodução de ignorância" (GRUSCHKA, 2014, p. 6).

O autor revela duas formas de didática que culminaram em sucesso e fracasso: a orientação por competências e a aprendizagem por compreensão. Gruschka (2014, p. 7) ainda explica a diferença entre as formas de didática a começar pela segunda, ensino da 
compreensão, que “[...] visa a compreensão dos conteúdos da educação que revelam as questões do mundo, a outra apenas treina conhecimento e métodos de aquisição de conhecimento com os quais a assimilação das tarefas alternadas possa ser realizada".

O caminho para a educação em sala de aula é para o autor "aprender a entender". Assim como para Adorno (1996) a saída para a semiformação é a autorreflexão crítica. “Aprender a entender” é, para Gruschka (2014, p. 11),

[...] uma descrição do ensino escolar geral, que não consiste apenas em meros discursos, mas como uma celebração abstrata dos conteúdos do ensino clássico, formal, material ou também da educação da OCDE ou da modelagem de um ensino educador como ideal na sucessão do Herbart e não também no modelo de ensino de didática, que exemplifica como é possível deixar os alunos desenvolverem alguma coisa de modo educativo, mas na capacidade de reunir uma série de operações pedagógicas numa sequência apropriada, principalmente in situ, ou seja, segundo a estrutura de aula.

O método de Gruschka (2014, p. 23-24) para concretizar a Didática Crítica em sala de aula consiste em atingir três desafios pedagógicos: educação, didática e formação. $\mathrm{Na}$ educação, o estudante aprende “[...] a assumir responsabilidades por si próprio e, através delas, a permitir também a constituição de um comportamento emancipado. Uma pessoa independente é [...] alguém que é capaz de julgar e criticar”. Na didática, o desafio é ligar o que está sendo transmitido ao que é compreendido. Por isso, “[...] a segunda obrigação da aula é a representação daquilo que deve ser ensinado, cujos conteúdos não podem ser inseridos como fenômenos iniciais” (GRUSCHKA, 2014, p. 25). Por último, a formação “[...] consiste. Finalmente. na interiorização dos assuntos de modo que signifiquem para os estudantes mais do que uma habilidade ou conhecimento" (GRUSCHKA, 2014, p. 28).

A proposta de Gruschka se assimila a várias iniciativas difundidas em muitos países, inclusive no Brasil, que democratizam o pensamento crítico ao provocar os alunos na reflexão das deficiências do ambiente escolar e induzirem ao trabalho em novas metodologias didáticas que aprofundem a análise dos panoramas sociais e humanos, que vão além do simples aprendizado da técnica e das operações. Portanto, a partir dessa proposta, a reforma da educação derrubaria as estruturas já estabelecidas, revelando-se com um ganho para a 
sociedade em geral, já que o que se aprende em sala de aula se reflete fora dela também. Nesse sentido, Carlino (2012) defende que mudanças profundas no ensino e na cultura institucional refletiriam na forma em que os alunos aprendem. Assim, segundo Antunes (2015), a Universidade seria o lugar no qual o processo educativo não pode se separar da crítica e da experimentação.

\section{CONSIDERAÇÕES FINAIS}

Contemporaneamente, as universidades entraram em um processo gradativo de empobrecimento reflexivo, evidenciado no acúmulo de pesquisas sobre assuntos muito específicos ou prescindíveis, totalmente ausentes de provocações filosóficas que explorem ao máximo a capacidade da existência humana e sua autoria na constituição de um melhor e mais justo panorama social. Neste contexto, este trabalho reuniu as contribuições de Adorno (1996) e Gruschka (2014) a uma formação que dê condições de resistência frente à semiformação através da pedagogia crítica.

Ao pensar esse artigo, algumas perguntas que também estão presentes no trabalho de Correia (2016, p. 124) nortearam a pesquisa:

Como pensar, portanto, uma formação que possibilite ao sujeito a sua emancipação? Em quem nos "referenciarmos" (ou em que conceito?) num cenário de pleno império da indústria, da técnica e da supremacia do capital? (...). É preciso romper, no entanto, com o império da semiformação. Mas como? Não seria com uma educação política que nos "autonomize" para a crítica?

A partir dos questionamentos acima e d o referencial teórico exposto nas sessões anteriores, apresentou-se os estudos empíricos de Gruschka (2014) como um aporte de resistência contra a semiformação. Nesse sentido, "o grupo de trabalho do Prof. Gruschka desenvolve pesquisas empíricas que procuram reconstruir o sentido pedagógico da educação, a partir do sentido dialético da formação, que se manifesta concretamente nas aulas" (GOMES, 2015, p.153). Ao se usar a teoria pedagógica proposta por Gruschka (2014) à luz dos estudos críticos de Adorno (1996) é possível identificar a melhor forma de aplicação da didática em sala de aula e também prever quando os elementos ali apresentados não são aspectos da formação. Portanto, essa teoria auxilia que os aspectos críticos prevaleçam sobre 
a semiformação, ou seja, “o que podemos apontar, são as condições favoráveis e aquelas que inibem a compreensão" (GRUSCHKA, 2014, p. 8).

Concomitantemente, os estudos adornianos alinhados com a compreensão do ambiente escolar deixam clara a

[...] necessidade do compromisso da escola com a construção de uma sociedade justa, denunciada pela forma como a instituição escolar operava o processo de massificação, e impedia a experiência formativa autêntica das pessoas, que desejavam uma vida mais digna e feliz. Nesse caso, a crítica e a negação determinada se constituem como uma exigência ética e política (GOMES, 2015, p. 153).

Utilizando uma metáfora biológica, existe hoje, portanto, a simples 'capilarização' do conhecimento e não um aumento da compreensão, o que ocasiona a pulverização do saber. Norteada pela acirrada concorrência presente no mercado de trabalho, a educação se torna uma vantagem competitiva para o alcance das melhores posições. Assim, a cultura de massas e a semiformação amalgamadas na educação sepultam a consciência reflexiva e empírica do ser humano, fazendo com que o sujeito se sinta impotente diante da realidade na qual se insere. $\mathrm{O}$ grande problema é que, nos dias atuais, a educação que deveria cumprir fielmente seu papel de 'chave' para a saída desse ciclo vicioso, se torna a principal via de empobrecimento pedagógico.

A relevância desse estudo foi trazer a discussão para o ambiente de ensino, reavivar na academia a mudança que a educação suplica, resgatar o seu potencial de conscientização e denunciar a massificação cultural que invadiu as escolas e sepultou a consciência reflexiva . O desafio para a educação contemporânea é abrir-se para a reflexão crítica quando seu ambiente já está tomado pelo semiformação.

\section{REFERÊNCIAS}

ACOSTA, H. P.; TOBÓN, S.; LOYA, J. L. Docencia socioformativa y desempeño académico en la educación superior. Paradigma, v. 36, n. 1, p. 42-55, 2015. Disponível em: $<$ http://revistas.upel.edu.ve/index.php/paradigma/article/view/2653>. Acesso em: 17 out. 2017. 
ADORNO, Theodor W. Teoria da semicultura. Educação e Sociedade, v. 56, n. 10, p. 388411, 1996.

ANTUNES, D. C. An aesthetic challenge to education: against a damaged subjectivity. In: International Herbert Marcuse Society Conference, Annals..., Salisbury, 2015.

BANDEIRA, B. S.; OLIVEIRA, A. R. Formação cultural e semiformação: contribuições de Theodor Adorno para pensar a educação hoje. Educação, v. 35, n. 2, p. 225-232, 2012. Disponível em: < http://www.redalyc.org/html/848/84823364010/>. Acesso em: 17 out. 2017.

CARLINO, P. Leer textos científicos y académicos en la educación superior: obstáculos y bienvenidas a una cultura nueva. Unipluriversidad, v. 3, n. 2, p. 17-23, 2012. Disponível em: < https://aprendeenlinea.udea.edu.co/revistas/index.php/unip/article/view/12289>. Acesso em: 17 out. 2017.

CARVALHO, J. M. G. V. de. Competência e Desempenho: avaliação e administração da formação. Sem Aspas, Araraquara, v. 2, n.1, p. 43-55, 2013. Disponível em: <http://seer.fclar.unesp.br/semaspas/article/view/6923>. >. Acesso em: 17 out. 2017. CORREIA, F. C. Theodor Adorno e problema da (semi) formação. Kínesis-Revista de Estudos dos Pós-Graduandos em Filosofia, v. 8, n. 16, p. 110-126, 2016. Disponível em: $<$ http://200.145.171.5/revistas/index.php/kinesis/article/view/6419>. Acesso em: 17 out. 2017.

GOMES, L. Teoria Crítica da Educação: experiências atuais de pesquisa no Brasil e na Alemanha. Comunicações, Brasil, v. 22, n. 3, p. 145-154, 2015. Disponível em: < https://www.metodista.br/revistas/revistasunimep/index.php/comunicacoes/article/view/2478/1643>. Acesso em: 17 out. 2017. GUIMARÃES, L. T.; SANTANA, M. S. R.; MOTTA, G. M. Políticas educacionais para a educação básica no Brasil: entre o pleno desenvolvimento e a semiformação. Revista IberoAmericana de Estudos em Educação, v. 7, n. 2, p. 32-42, 2012. Disponível em: < http://piwik.seer.fclar.unesp.br/iberoamericana/article/view/5390 >. Acesso em: 17 out. 2017. GRUSCHKA, A. Teoria Crítica e pesquisa empírica em educação: a escola e a sala de aula. Constelaciones. Dossiê: Teoria Critica de La Sociedad y Educación, v. 6, n. 6, p. 3-31, 2014. Disponível em: <http://constelaciones-rtc.net/article/view/851>. Acesso em: 17 out. 2017. GRUSCHKA, A.; HERRMANN, U. et al. Il sistema formativo non èun'azienda Cinqueobiezionicontrolariorganizzazionetecnocraticadel sistema formativo. Topologik Rivista Internazionale di Scienze Filosofiche, Pedagogiche e Sociali, v. 184, n. 10, p. 184187, 2011. Disponível em: 


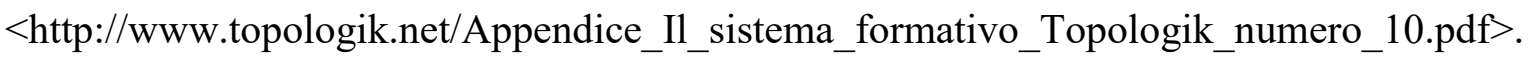
Acesso em: 17 out. 2017

GRUSCHKA, A.; HERRMANN, U. et al. Pedagogia negativa como crítica da pedagogia. In: PUCCI, B.; ALMEIDA, J.; LASTÓRIA, L. A. C. N. (Orgs.) Experiência formativa e emancipação. São Paulo: Nankin, p. 137-162, 2009.

HARGREAVES, A. Profesorado, cultura y postmodernidad: cambian los tiempos, cambia el profesorado. Madrid: Ed. Morata, 1996.

LASTÓRIA, L. C. N.; DA SILVEIRA, B. P.; RODEGUERO, J. S.; FLEIRIA, J P.; DUCI, J.. Teoria crítica da sociedade: um olhar sobre a educação em tempos de sociedade tecnológica. Conjectura: filosofia e educação, Caxias do Sul, v. 18, n. 1, p. 164-178, jan./abr. 2013. Disponível em: <http://www.ucs.br/etc/revistas/index.php/conjectura/article/view/2046>. Acesso em: 17 out. 2017.

NEWMAN, M. Z. Swift viewing: the popular life of subliminal influence. Screen, v. 56, n. 3, p. 378-380, 2015. Disponível em: <

https://academic.oup.com/screen/article/56/3/378/1860915/Swift-Viewing-The-Popular-Lifeof-Subliminal>. Acesso em: 17 out. 2017.

ORDORIKA, I.; LLOYD, M. Teorías críticas del Estado y la disputa por la educación superior en la era de la globalización. Perfiles Educativos, v. 36, n. 145, p. 122 -139, 2014. Disponível em: < http://www.sciencedirect.com/science/article/pii/S0185269814706415>. Acesso em: 17 out. 2017.

PAULA, A. P. De P.; RODRIGUES, M. A. Pedagogia crítica no ensino da administração: desafios e possibilidades. Revista de Administração de Empresas, v. 46, s.n., p. 10-22, 2006. Disponível em: < http://www.scielo.br/scielo.php?pid=S0034$75902006000500001 \&$ script=sci_arttext $>$. Acesso em: 17 out. 2017. PUCCI, B. A Escola e a semiformação mediada pelas novas tecnologias. In: PUCCI, B. (Org.). LASTÓRIA, L. A. C. Na.(Org.). Experiência formativa \& emancipação. 1 ed. São Paulo: Nankin, p. 69-80, 2009. Disponível em: <http://www.unimep.br/ bpucci/a-escola-e-asemiformacao.pdf $>$. Acesso em: 17 out. 2017.

PUCCI, B. Teoria crítica e educação: contribuições da teoria crítica para a formação do professor. Espaço Pedagógico, v. 8, s.n., p. 13-30, 2001. Disponível em: $<$ http://www.unimep.br/ bpucci/teoria-critica-e-educacao.pdf $>$. Acesso em: 17 out. 2017. SARAIVA, L. A. A. A educação superior em administração no Brasil e a questão da emancipação: um túnel no fim da luz? Gestão \& Planejamento-G\&P, v. 12, n. 1, p. 41-60, 
2011. Disponível em: <http://www.revistas.unifacs.br/index.php/rgb/article/view/1296>. Acesso em: 17 out. 2017.

TRANIER, J. Educación para la Emancipación. Notas para pensar $<$ Para qué educar $>$, em contextos de despersonalización y desarticulación social. Nómadas Revista Crítica de Ciencias Sociales y Jurídicas, s.v., s.n., s.p., 2013. Disponível em:

$<\mathrm{http}$ ://pendientedemigracion.ucm.es/info/nomadas/americalatina2012/josetranier.pdf $>$. Acesso em: 17 out. 2017.

VILELA, R. A. T.; NOACK-NAPOLES, J. "Hermenêutica Objetiva" e sua apropriação na pesquisa empírica na área de educação. Linhas Críticas, v. 16, n. 31, p. 305-326, 2010. Disponível em: $<$ http://periodicos.unb.br/index.php/linhascriticas/article/view/3027>. Acesso em: 17 out. 2017.

2017.

VILELA, R. A. T. A pesquisa empírica da sala de aula na perspectiva da teoria crítica: aportes metodológicos da Hermenêutica Objetiva de Ulrich Oevermann. In: PUCCI, B; COSTA, B. C. G; DURÃO, F. A. (Orgs). Teoria Crítica e crises: reflexões sobre cultura, estética e educação.São Paulo: Autores Associados, p. 1-22, 2012. Disponível em: < http://www.ich.pucminas.br/pged/arquivos/publica/ratv/pesqempirica_aportesmet_Oerverma nn.pdf>. Acesso em: 16 fev. 2018.

VILELA, R. A. T. A presença da Teoria Crítica no debate e na pesquisa educacional no Brasil e na Alemanha no período de 1995 à atualidade. Belo Horizonte: PUC Minas. Programa de Pós-Graduação em Educação, Relatório de Pesquisa, p. 1-132, 2009. Disponível em:

$<\mathrm{http}$ //www2.pucminas.br/imagedb/mestrado_doutorado/publicacoes/PUA_ARQ_ARQUI20 120828095538.pdf>. Acesso em: 27 out. 2017.

VILELA, R. A. T. A Teoria Crítica da educação de Theodor Adorno e sua apropriação para análise das questões atuais sobre currículo e práticas escolares. Belo Horizonte:

CNPQ (Relatório de Pesquisa), p. 119-133, 2006. Disponível em: < http://ws4.pucminas.br/imagedb/mestrado_doutorado/publicacoes/PUA_ARQ_ARQUI20120 828100151.pdf>. Acesso em: 17 out. 2017. 